\title{
Cryptosporidium genotypes in children and calves living at the wildlife or livestock interface of the Kruger National Park, South Africa
}

\begin{tabular}{|c|c|}
\hline Authors: & \\
\hline Nada Abu San & $\mathrm{ra}^{1}$ \\
\hline Ferran Jori' & \\
\hline Simone M. Ca & cciò ${ }^{4}$ \\
\hline John Frean ${ }^{5,6}$ & \\
\hline Bhavani Poon & amy $y^{5}$ \\
\hline Peter N. Thom & pson $^{1}$ \\
\hline $\begin{array}{l}\text { Affiliations: } \\
{ }^{1} \text { Department }\end{array}$ & f Production \\
\hline $\begin{array}{l}\text { Animal Studie } \\
\text { Pretoria, Sout }\end{array}$ & $\begin{array}{l}\text { s, University of } \\
\text { Africa }\end{array}$ \\
\hline${ }^{2}$ French Resea & rch Institute for \\
\hline $\begin{array}{l}\text { Agricultural D } \\
\text { (CIRAD), Integ }\end{array}$ & $\begin{array}{l}\text { evelopment } \\
\text { rated Animal }\end{array}$ \\
\hline Risk Managen & lent Unit (UPR \\
\hline $\begin{array}{l}\text { AGIRs), Camp } \\
\text { de Baillarguet }\end{array}$ & $\begin{array}{l}\text { «s International } \\
\text { France }\end{array}$ \\
\hline $\begin{array}{l}{ }^{3} \text { Department } \\
\text { Science and P } \\
\text { Botswana Col } \\
\text { Agriculture, B }\end{array}$ & $\begin{array}{l}\text { f Animal } \\
\text { oduction, } \\
\text { ege of } \\
\text { tswana }\end{array}$ \\
\hline $\begin{array}{l}{ }^{4} \text { Department } \\
\text { Parasitic and } \\
\text { Immunomedi } \\
\text { Diseases, Istit } \\
\text { di Sanità, Italy }\end{array}$ & $\begin{array}{l}\text { f Infectious, } \\
\text { ted } \\
\text { to Superiore }\end{array}$ \\
\hline $\begin{array}{l}{ }^{5} \text { Centre for Op } \\
\text { Tropical and } \\
\text { Infections, Na } \\
\text { for Communic } \\
\text { South Africa }\end{array}$ & $\begin{array}{l}\text { portunistic, } \\
\text { ospital } \\
\text { ional Institute } \\
\text { able Diseases, }\end{array}$ \\
\hline $\begin{array}{l}{ }^{6} \text { Research Inst } \\
\text { Malaria, Unive } \\
\text { Witwatersran }\end{array}$ & $\begin{array}{l}\text { tute for } \\
\text { rsity of the } \\
\text {, South Africa }\end{array}$ \\
\hline $\begin{array}{l}\text { Correspondin } \\
\text { Nada Abu San } \\
\text { nada.nada@g }\end{array}$ & $\begin{array}{l}\text { author: } \\
\text { ra, } \\
\text { nx.de }\end{array}$ \\
\hline $\begin{array}{l}\text { Dates: } \\
\text { Received: } 30 \text { J } \\
\text { Accepted: } 02 \\
\text { Published: } 20\end{array}$ & $\begin{array}{l}\text { Uly } 2015 \\
\text { Mec. } 2015 \\
\text { May } 2016\end{array}$ \\
\hline Read online: & \\
\hline 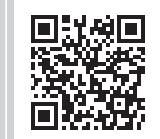 & $\begin{array}{l}\text { Scan this QR } \\
\text { code with your } \\
\text { smart phone or } \\
\text { mobile device } \\
\text { to read online. }\end{array}$ \\
\hline
\end{tabular}

Cryptosporidium infection is one of the most common causes of parasitic diarrhoea worldwide in cattle and humans. In developing countries, human cryptosporidiosis is most prevalent during early childhood and links between zoonotic infection and animal related activities have been demonstrated. This study investigated the prevalence and species/genotype distribution of Cryptosporidium among children ( $<5$ years) and calves ( $<6$ months) living in a rural farming area adjacent to the Kruger National Park in South Africa, where interactions between humans and wild and domestic animals are known to occur. Cryptosporidium oocysts were detected in $8 / 143$ stool samples of children recruited within the hospital system $(5.6 \% ; 95 \%$ CI $2.4 \%, 10.7 \%)$ and in $2 / 352$ faecal samples of calves $(0.6 \%$; $95 \%$ CI $0.1 \%, 2.0 \%)$ using the modified Ziehl-Neelsen (MZN) staining technique. Microscopy positive samples from children were further analysed by PCR targeting the 18S rRNA gene and identified as Cryptosporidium hominis (3/4) and Cryptosporidium meleagridis (1/4). Regardless of the microscopy outcome, randomly selected samples $(n=36)$ from calves $0-4$ month of age were amplified and sequenced at the $18 \mathrm{~S}$ rRNA gene using nested PCR. Two calves tested positive (5.6\%; 95\% CI 1.7\%, 18.7\%), and revealed the presence of Cryptosporidium parvum and Cryptosporidium bovis. The detection of only two zoonotic species (C. parvum in one calf and C. meleagridis in one child) suggests that zoonotic cryptosporidiosis is not currently widespread in our study area; however, the potential exists for amplification of transmission in an immunocompromised population.

\section{Introduction}

Cryptosporidium spp. are Apicomplexan parasites that infect a wide range of vertebrates, including humans. Cryptosporidiosis is associated with mild to severe diarrhoea that is typically self-limiting in immunocompetent hosts, but can become chronic and life-threatening in immunocompromised and very young individuals (Ramirez, Ward \& Sreevatsan 2004).

Humans are most commonly infected by Cryptosporidium parvum, which primarily infects cattle and may be of either zoonotic or anthroponotic origin, and by Cryptosporidium hominis, which primarily infects humans. Other species of Cryptosporidium, including Cryptosporidium meleagridis, Cryptosporidium felis, and Cryptosporidium canis, are responsible for a smaller number of infections in humans and have mainly been reported in immunosuppressed patients (Xiao \& Feng 2008). More recently, C. meleagridis has been recognised as an emerging human pathogen (Putignani \& Menichella 2010; Xiao 2010) and was responsible for up to $10 \%$ of all infections in developing countries (Gatei et al. 2006; Xiao 2010).

The zoonotic importance of Cryptosporidium spp. has been recognised for some time (Xiao \& Feng 2008); however, the role of wild and domestic animals in the epidemiology of human cryptosporidiosis, particularly in developing countries, is not completely understood. C. parvum is the only species of zoonotic importance identified in cattle and several outbreaks of C. parvum in people have been associated with infected calves in the United States and the United Kingdom (Gait et al. 2008; Kiang et al. 2006; Smith et al. 2004). In Africa, specifically in Egypt and Ethiopia, contact with cattle has been identified as a significant risk factor for the zoonotic transmission of C. parvum in children and HIV and/or AIDS patients (Adamu et al. 2014; Helmy et al. 2013).

How to cite this article: Abu Samra, N., Jori, F., Cacciò, S.M., Frean, J., Poonsamy, B. \& Thompson, P.N., 2016, 'Cryptosporidium genotypes in children and calves living at the wildlife or livestock interface of the Kruger National Park, South Africa', Onderstepoort Journal of Veterinary Research 83(1), a1024. http://dx.doi.org/10.4102/ojvr.v83i1.1024

Copyright: ( 2016 . The Authors. Licensee: AOSIS. This work is licensed under the Creative Commons Attribution License. 
In South Africa, cryptosporidiosis has been reported in humans and livestock in various locations. In diarrhoeic children a prevalence of $24.8 \%$ was found in a hospital in Durban (Leav et al. 2002), and more recently an overall prevalence of $12.2 \%$ was reported in hospitalised diarrhoeic children from four different provinces, with a prevalence of $8.6 \%$ in one of the four hospitals located in close proximity to our study area (Abu Samra et al. 2013a). The predominant species found in both studies was $C$. hominis, with five different GP60 subtype families (Ia, Ib, Id, Ie, and If), followed by anthroponotic forms of C. paroum (IIc, IIe, and $\mathrm{IIb})$; this supported previous findings that suggested that cryptosporidiosis in developing countries is predominantly of anthroponotic origin (Mor \& Tzipori 2008; Xiao 2010). In cattle, data on cryptosporidiosis are scarcer: a prevalence of $33.6 \%(36 / 107)$ with Cryptosporidium spp. has been reported in adult cattle from the southern Free State Province, South Africa (Bakheit et al. 2008) and, more recently, a study conducted in a different area adjacent to the Kruger National Park (KNP) reported a prevalence of $8 \%(4 / 51)$ in weaned calves, with Cryptosporidium bovis and Cryptosporidium andersoni as circulating genotypes (Abu Samra et al. 2013b).

Because no simultaneous investigation on Cryptosporidium spp. in young children and animals living at the wildlife/ livestock/human interface has been undertaken to date, the objective of this study was to estimate the prevalence and study the genetic diversity of Cryptosporidium spp. and to identify potential risk factors associated with cryptosporidiosis in young children and calves in an area of the KNP wildlife/ livestock/human interface.

\section{Materials and methods Study site}

The study took place in a communal farming area, the Mnisi Traditional Authority (MTA), situated in a rural environment in the north-eastern Lowveld area of Mpumalanga Province, South Africa, adjacent to private protected wildlife areas continuous with the KNP (Figure 1). In this area, livestock production is a prevalent activity among rural communities, and contact between cattle and wildlife occurs (Abu Samra et al. 2011, 2013a; Brahmbhatt et al. 2009). The local presence of Cryptosporidium spp. in cattle and wildlife in the area had previously been reported (Abu Samra et al. 2013a).

In this community, subsistence farmers rely mostly on livestock farming, the most common livestock being the indigenous Nguni cattle, used for milk and meat production. Cattle dip tanks have been established throughout the region, and every cattle herd is taken for dipping and inspection once a week to control tick-borne diseases (Simela 2012). The MTA community hosts a population of more than 40000 people and eight human health centres are located within this community. It is estimated that approximately $34 \%$ of the human population of MTA is infected with human immunodeficiency virus (HIV) (Moshabela et al. 2011).

\section{Ethical consideration}

This study was approved by the Animal Use and Care Committee of the University of Pretoria (Protocol V014/08) for animal sampling, and by the Research Ethics Committee of the University of Pretoria for human sampling (Protocol no. 5/2011). Before initiating the work, all stakeholders were contacted in order to seek their permission. Animal health technicians and a local field assistant assisted in informing all cattle owners of the purpose of this study and that participation was voluntary. Nurses at participating health care centres informed their patients of the purpose of the study and if parents agreed to their child's participation, a consent form was signed. Finally, stool samples were collected with parental consent and on a voluntary basis in collaboration with nurses working at each of the clinics.

\section{Sample collection}

From March to June 2012, during autumn, at the end of the rainy season and the start of the dry season, stool samples from 143 children $<5$ years old were collected by convenience sampling from six rural clinics in the study area, without specific consideration for gender or reported symptoms. The parents of each participant were asked to complete a brief questionnaire to gather information on their child's age, contacts with domestic animals, source of drinking water, whether water was boiled before drinking, and history of diarrhoea since birth.

Simultaneously, 352 faecal samples were collected from preweaned calves ( $<6$ months of age) at 11 dip tanks in the study area. A sample size was calculated to estimate a $5 \%$ prevalence with $2.5 \%$ allowable error, using the formula $n=1.96^{2} P Q / L^{2}$ (Thrusfield 2007), where $P$ is the estimated prevalence (0.05), $Q=1-P$ and $L$ is the absolute allowable error (0.025), giving a required minimum sample size of 292 . Faecal samples were collected directly from the rectum of calves and each dip tank was visited only once to avoid repeated sampling of individual calves. A brief questionnaire was completed by interviewing the herdsman accompanying each sampled animal. Closed questions (dichotomous and multiple choice) for ascertaining age, herd size, and source of drinking water were used.

All faecal samples from children and calves were transported on ice to the National Institute for Communicable Diseases (NICD) in Johannesburg, where they were preserved in 2.5\% potassium dichromate and stored at $4{ }^{\circ} \mathrm{C}$ until processed.

\section{Laboratory analysis}

At the NICD faecal samples from calves and children were concentrated by the formalin-ethyl acetate sedimentation method and thin smears were stained using the modified Ziehl-Neelsen (MZN) technique (Garcia 2001). The stained slides were examined by light microscopy with immersion oil using 50x and 100x objectives to detect Cryptosporidium spp. oocysts. Because of limited resources only MZN-positive 


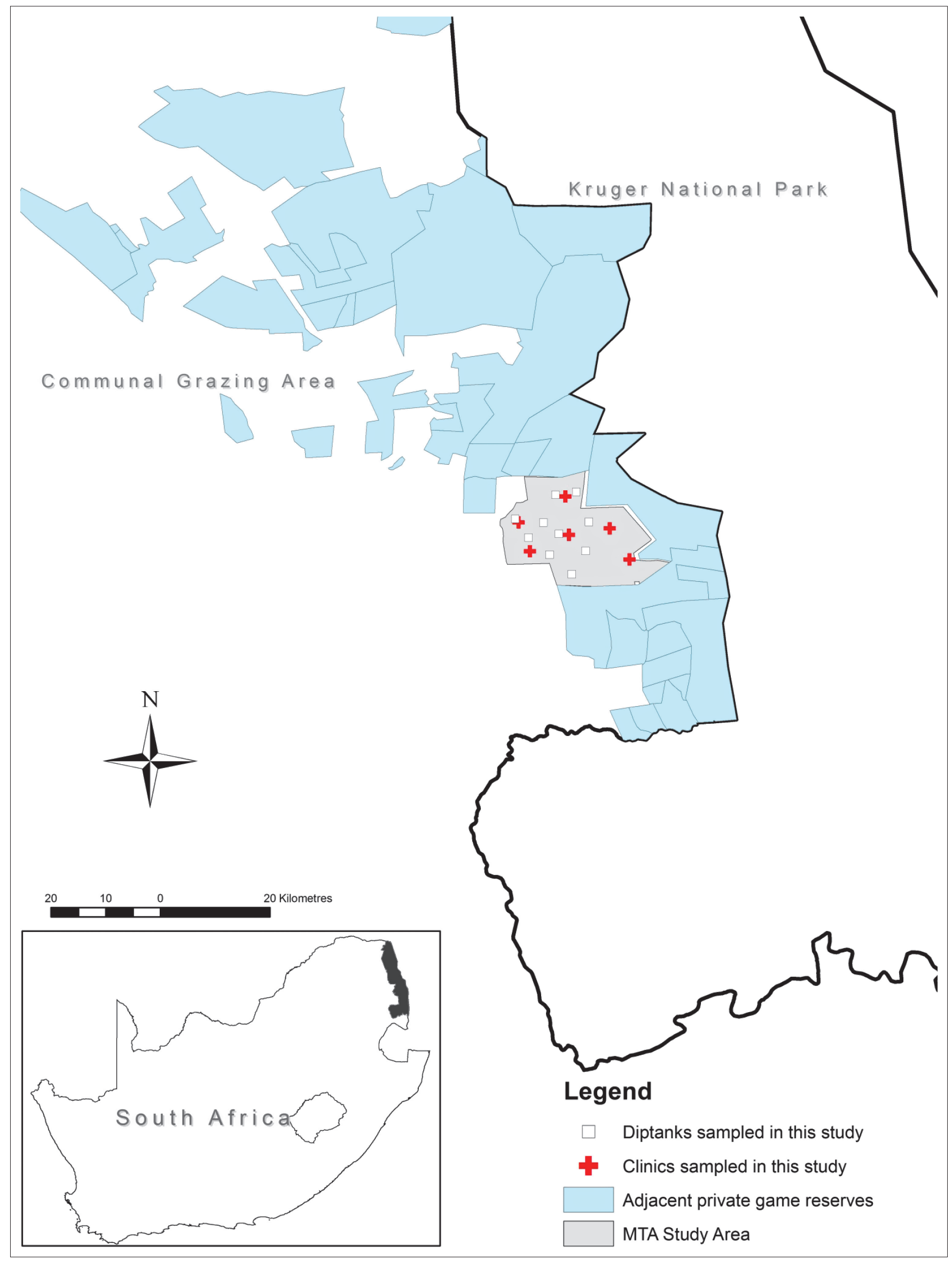

Source: Author's (Ferran Jori) own creation

FIGURE 1: Study area for the location of clinics and dip tanks where sampling took place. 
faecal samples of children $(n=8)$ were sent to the European Union Reference Laboratory for Parasites at the Instituto Superiore di Sanità in Rome, Italy, for molecular analysis. Of the calf samples, only those from animals within the $0-4$ month age group were further analysed; 36 samples of this age category were randomly selected for molecular analysis, irrespective of their MZN outcome.

\section{DNA extraction}

Prior to DNA extraction, Cryptosporidium oocysts were purified from the faeces by caesium chloride gradient. Purified oocysts were suspended in $25 \mu \mathrm{L}$ of buffer $(10 \mathrm{mM}$ Tris $\mathrm{pH} 8.3,50 \mathrm{mM} \mathrm{KCl}$ containing $0.5 \% \mathrm{w} / \mathrm{v}$ Tween 20). After freeze-thawing (15 cycles), samples were heated for $15 \mathrm{~min}$ at $100{ }^{\circ} \mathrm{C}$ and then centrifuged for $2 \mathrm{~min}$ at $13000 \mathrm{rpm}$ to remove particulate matter. Finally, $2 \mu \mathrm{L}-5 \mu \mathrm{L}$ of supernatant was used for PCR amplification (Bonnin et al. 1996).

\section{Amplification and genotyping at the 18S rRNA locus}

The extracted DNA of samples from children $(n=8)$ and calves $(n=36)$ were amplified at the $18 \mathrm{~S}$ rRNA gene using a two-step nested PCR assay as previously described. In short, a primary PCR product of $760 \mathrm{bp}$ was amplified and for the secondary PCR a fragment of about $590 \mathrm{bp}$ was amplified (Ryan et al. 2003). The amplified 18S rRNA gene fragment was analysed by electrophoresis on $2 \%$ agarose gels, stained with ethidium bromide and visualised under a UV transilluminator. The secondary PCR products were purified and sequenced on both strands. Sequences were assembled using the software SeqMan version 7.1 (DNASTAR, Inc.) and compared with those available in GenBank using BLAST software (Pruitt, Tatusova \& Maglott 2005).

\section{Cryptosporidium amplification and sequencing of the GP60 gene}

DNA of all samples identified as C. hominis were then amplified at the GP60 gene, using external primers (Strong, Gut \& Nelson 2000) and internal primers (Drumo et al. 2012). PCR products were purified using spin columns and sequenced on both strands. Sequences were assembled using SeqMan version 7.1 (DNASTAR, Inc.). A BLAST search against the GenBank database was used to identify $C$. hominis GP60 subtypes.

\section{Statistical analysis}

Data were entered into a spreadsheet and then analysed using Epi-Info (Version 3.3.2., CDC Atlanta, 2005) and Stata 12.1 (StataCorp, College Station, TX, USA). Prevalences were calculated with 95\% exact binominal confidence limits. The bivariable association of each variable (potential risk factor and history of diarrhoea) with Cryptosporidium infection was assessed separately for calves and for children using Fisher's exact test. In addition, all potential risk factors were entered into multivariable exact logistic regression models to adjust for confounding. Statistical significance was assessed at $P<0.05$.

\section{Results Children}

From faecal samples of 143 children, eight were found positive by the MZN staining method and were confirmed by PCR. Therefore, the prevalence of Cryptosporidium infection in children was estimated to be $5.6 \%$ (95\% CI 2.4\%, 10.7\%). At least one positive sample was detected in children in five out of the six clinics surveyed.

Four of the eight $18 \mathrm{~S}$ rRNA PCR-positive samples were successfully sequenced and C. hominis (3/4) and C. meleagridis $(1 / 4)$ were identified. Sequence analysis of the GP60 gene was done for the $C$. hominis isolates and two subtype families were identified, namely $\mathrm{Ib}$ (IbA12G3R2 and IbA10G2) and Ie (IeA11G3T3). Sequences were deposited in GenBank (Submission ID 1871551).

Bivariable associations were assessed with potential risk factors from 141 questionnaires (two interviews were not completed) (Table 1). Details on diarrhoeic episodes were not systematically reported and therefore only history of diarrhoea was considered during the analysis. The univariable associations of the five potential risk factors with the presence of Cryptosporidium in children were not significant; likewise, the exact logistic regression model was unable to detect significant associations between any of the factors and Cryptosporidium infection.

\section{Calves}

Only $2 / 352$ calf samples $(0.6 \% ; 95 \%$ CI $0.1 \%, 2.0 \%)$ were positive by MZN and of the 36 calves $<4$ months of age randomly selected for $18 \mathrm{~S}$ rRNA nested PCR (which did not include the two MZN-positive samples) two were positive, giving an estimated prevalence of 5.6\% (95\% CI 1.7\%, 18.7\%). None of the univariable associations of the three potential risk factors with the presence of Cryptosporidium in calves were significant and the exact logistic regression model was unable to detect any significant associations.

Sequencing of the $18 \mathrm{~S}$ rRNA gene PCR product revealed the presence of C. parvum (100\% homology to many C. paroum

TABLE 1: Potential risk factors associated with Cryptosporidium infection in 143 children $<5$ years old: Results of a multivariable exact logistic regression model.

\begin{tabular}{lcccc}
\hline Variable & Level & Odds ratio & $\mathbf{9 5 \%}$ Cl (OR) & $\boldsymbol{P}$ \\
\hline Age & $0-2$ months & $1 \dagger$ & - & - \\
& $<6$ months & 0.62 & $0.01,55.7$ & 1.000 \\
& $6-12$ months & 0.89 & $0.07,51.2$ & 1.000 \\
& $>12$ months & 0.34 & $0.01,26.7$ & 0.880 \\
Contact with cattle & No & $1 \dagger$ & - & - \\
& Yes & 0.87 & $0.07,7.10$ & 1.000 \\
Contact with other & No & $1 \dagger$ & - & - \\
animals (cat, dog, goat) & Yes & 1.31 & $0.17,15.5$ & 1.000 \\
Source of drinking & other & $1 \dagger$ & - & - \\
water & tap & 0.08 & $0.002, \infty$ & 1.000 \\
Boiling water before & No & $1 \dagger$ & - & - \\
drinking & Yes & 1.09 & $0.01,20.3$ & 1.000 \\
\hline$\dagger$, Reference level. & & & &
\end{tabular}


sequences, e.g. KJ719487) and C. bovis (100\% homology to many C. bovis sequences, e.g. KJ531689) in the two positive samples.

\section{Discussion}

The prevalence of Cryptosporidium spp. infection detected in children and calves in this study is lower compared to previous studies conducted in southern Africa (Samie et al. 2006; Siwila et al. 2011). Cryptosporidiosis is recognised as an important disease in children and immunosuppressed adults in subSaharan Africa (Mor \& Tzipori 2008), but with a widely varying prevalence. In Uganda, for example, a prevalence of $25 \%$ was detected among diarrhoeic children and of $8.5 \%$ among non-diarrhoeic children (Tumwine et al. 2003). Cryptosporidium was identified in Tanzania in 13 and $9 \%$ of children with acute and chronic diarrhoea respectively, but no oocysts were detected in children without diarrhoea (Cegielski et al. 1999). In South Africa, cryptosporidiosis has been reported by different studies at prevalence ranging between $12 \%$ and $25 \%$ of hospitalised diarrhoeic children, including a prevalence of 8.6\% (11/128) in Agincourt Hospital, located within $20 \mathrm{~km}$ from our study area (Abu Samra et al. 2013b; Leav et al. 2002).

The prevalence of Cryptosporidium spp. in calf samples was low compared to studies targeting calves of a similar age group elsewhere in Africa. In Nigeria, for instance, a prevalence of $16 \%$ was reported in native cattle less than 1 year of age (Maikai et al. 2011). In Zambia, 48\% of dairy calves and $6.3 \%$ of traditionally-raised calves, all less than 3 months of age and within the same study area, were found to be infected with Cryptosporidium, suggesting that native breeds of cattle from traditional husbandry systems may be more resistant to Cryptosporidium infection compared to intensively raised cattle (Geurden et al. 2006).

The lower prevalence observed in children and calves in this study may be because our sampling did not specifically target diarrhoeic individuals, who are known to shed a high number of Cryptosporidium oocysts in their faeces (DuPont et al. 1995). The diagnostic method used for the detection of Cryptosporidium oocysts (MZN stain) has a reduced sensitivity for detecting Cryptosporidium in low-oocyst-shedding individuals. Indeed, other studies using more sensitive molecular techniques have shown considerably higher detection rates. In Uganda for instance, PCR was 32\% more sensitive in detecting Cryptosporidium oocysts than was MZN (Tumwine et al. 2003). In Egypt, human samples were analysed by non-molecular and PCR techniques and prevalences of $6.7 \%$ and $49 \%$ were detected, respectively (Helmy et al. 2013).

Another aspect that could have influenced our results is the period of sampling, which spanned the end of the rainy season and the start of the dry season. Seasonal variation of cryptosporidiosis in human and animals has been reported in a number of studies in southern and eastern Africa, such as in Malawi (Morse et al. 2007), Uganda (Tumwine et al. 2003), and Zambia (Nchito, Kelly \& Sianongo 1998), with the highest prevalence recorded during the rainy season.
Results of the PCR and sequencing analysis of the 18S rDNA gene identified C. hominis as the dominant species in children, which is in agreement with previous findings elsewhere in Africa (Akiyoshi et al. 2006; Gatei et al. 2007; Morse et al. 2007). Four $C$. hominis subtype families are most commonly observed in humans in developing countries: Ia, Ib, Id, and Ie (Xiao 2010). The C. hominis subtype family most frequently detected in this study was $\mathrm{Ib}(2 / 3)$, followed by Ie (1/3). Within the C. hominis subtype family $\mathrm{Ib}$, IbA10G2 has been previously described in South Africa, Peru, and India (Cama et al. 2008; Gatei et al. 2007; Leav et al. 2002) and was identical to the one identified in this study. Although the number of successfully sequenced samples (4/8) was too small to draw any conclusions, a recent study from a hospital located in close proximity to our study area, where a predominance of anthroponotic species (100\%) was found, is consistent with our findings (Abu Samra et al. 2013b).

Regarding zoonotic species, our study detected the circulation of C. meleagridis in one child and C. parvum in one calf. Cryptosporidium meleagridis, reported in a wide range of wild and domestic mammals, including rodents, cattle, and humans (Caccio 2005; Cama et al. 2008; Qi et al. 2011; Xiao 2010; Xiao et al. 2002), is regarded as an emerging human pathogen (Putignani \& Menichella 2010) and has been reported before in diarrhoeic children in South Africa (Abu Samra et al. 2013b). Likewise, C. parvum is known to be an important cause of zoonotic cryptosporidiosis worldwide (Gait et al. 2008; Hunter \& Thompson 2005; Kiang et al. 2006; Smith et al. 2004); however, the low prevalence of C. meleagridis and C. parvum detected during this study suggests that zoonotic cryptosporidiosis is currently not widespread in our study population.

We were not able to detect any association between animal contact and Cryptosporidium infection in children in our study; the low prevalence of cryptosporidiosis reduced the power of the statistical analysis to identify risk factors. The source of drinking water as a potential risk factor for Cryptosporidium infection in children and calves was one of the variables investigated during this study; however, pipeborne water was used by the large majority (99\%) of households interviewed, which suggests that water sources were generally not shared with animals, therefore reducing the probability of zoonotic infection in our studied community. Water-borne pathogens, such as Cryptosporidium spp. in rural communities in developing countries, can be amplified by seasonal water flows and flooding, which facilitate the common use of contaminated water sources between humans and animals (Alexander et al. 2013; Fenwick 2006). In a similar study assessing epidemiological and molecular interactions between humans, wildlife, and livestock in Uganda, fetching water from an open water source was suspected to increase the probability of cryptosporidiosis in humans (Salyer et al. 2012).

The fact that zoonotic cryptosporidiosis was detected in only one child and one calf suggests that zoonotic transmission 
may not be important in our study area. However, considering that the prevalence of HIV among rural communities in South Africa is among the highest in the world and was estimated to be $34 \%$ in our study area (Moshabela et al. 2011), the potential impact of the circulation of zoonotic strains in our study should be investigated further.

\section{Conclusion}

Considering that children and calves are good indicators of cryptosporidiosis in their respective populations, zoonotic cryptosporidiosis appears to occur at low levels in our studied community at the interface of the KNP. However, the detection of some zoonotic strains does not allow us to exclude a potential zoonotic risk and impact in an immunocompromised human population. Therefore, further studies should be undertaken, considering different spatiotemporal settings, using molecular diagnostic tools, and simultaneously assessing the prevalence of oocysts in domestic and wild animals, children, and water.

\section{Acknowledgements}

We are grateful to the Faculty of Veterinary Science, University of Pretoria, for providing funding for this research. We acknowledge the support provided by Rita van Deventer from the NICD, Johannesburg, and are very grateful to Joris Vink and Roos Zuurendonk from Utrecht University for their assistance during sample and data collection.

\section{Competing interests}

The authors declare that they have no financial or personal relationships which may have inappropriately influenced them in writing this article.

\section{Authors' contributions}

N.A.S. was the project leader and F.J. assisted during study design, data collection, and analysis. S.M.C. performed the molecular analysis. J.F. and B.P. performed microscopic analysis. P.N.T. was the main supervisor throughout the project and carried out statistical analysis.

\section{References}

Abu Samra, N., Jori, F., Samie, A. \& Thompson, P., 2011, 'The prevalence of Cryptosporidium spp. oocysts in wild mammals in the Kruger National Park, South Africa', Veterinary Parasitology 175, 155-159.

Abu Samra, N., Jori, F., Xiao, L., Rikhotso, O. \& Thompson, P.N., 2013a, 'Molecula characterization of Cryptosporidium species at the wildlife/livestock interface of the Kruger National Park, South Africa', Comparative Immunology, Microbiology and Infectious Diseases 36, 295-302.

Abu Samra, N., Thompson, N.P., Jori, F., John, F., Poonsamy, B., Du Plessis, D. et al., $2013 \mathrm{~b}$, 'Genetic characterization of Cryptosporidium spp. in diarrhoeic children from four provinces in South Africa', Zoonoses and Public Health 60, 154-159.

Adamu, H., Petros, B., Zhang, G., Kassa, H., Amer, S., Ye, J. et al., 2014, 'Distribution and clinical manifestations of Cryptosporidium species and subtypes in HIV/AIDS patients in Ethiopia', PLoS Neglected Tropical Diseases 8, 2831

Akiyoshi, D.E., Tumwine, J.K., Bakeera-Kitaka, S. \& Tzipori, S., 2006, 'Subtype analysis of Cryptosporidium isolates from children in Uganda', Journal of Parasitology 92, 1097-1100.

Alexander, K.A., Carzolio, M., Goodin, D. \& Vance, E., 2013, 'Climate change is likely to worsen the public health threat of diarrheal disease in Botswana', International Journal of Environmental Research and Public Health 10, 1202-1230.
Bakheit, M.A., Torra, D., Palomino, L.A., Thekisoe, O.M., Mbati, P.A., Ongerth, J. et al., 2008, 'Sensitive and specific detection of Cryptosporidium species in PCR-negative samples by loop-mediated isothermal DNA amplification and confirmation of generated LAMP products by sequencing', Veterinary Parasitology 158, 11-22.

Bonnin, A., Fourmaux, M.N., Dubremetz, J.F., Nelson, R.G., Gobet, P., Harly, G. et al., 1996, 'Genotyping human and bovine isolates of Cryptosporidium parvum by polymerase chain reaction-restriction fragment length polymorphism analysis of a repetitive DNA sequence', FEMS Microbiology Letters 137, 207-211.

Brahmbhatt, D.P., Fosgate, G.T., Dyason, E., Gummow, B., Jori, F., Budke, C., R. S. et al., 2009, 'Contacts between wildlife and livestock at the Kruger National Park interface of the Republic of South Africa', 12th International Symposium of Veterinary Epidemiology and Economics. Durban, South Africa, August 10-14, 2009.

Caccio, S., 2005, 'Molecular epidemiology of human cryptosporidiosis', Parassitologia 47, 185-192.

Cama, V.A., Bern, C., Roberts, J., Cabrera, L., Sterling, C., Ortega, Y. et al., 2008 'Cryptosporidium species and subtypes and clinical manifestations in children, Peru', Emerging Infectious Diseases 14, 1567-1574.

Cegielski, J.P., Ortega, Y.R., Mckee, S., Madden, J.F., Gaido, L., Schwartz, D.A. et 1999 'Cryptosporidium, Enterocytozoon, and Cyclospora infections in pediatric and adult patients with diarrhea in Tanzania', Clinical Infectious Diseases 28, 314-321.

Drumo, R., Widmer, G., Morrison, L.J., Tait, A., Grelloni, V., D’avino, N. et al., 2012, 'Evidence of host-associated populations of Cryptosporidium parvum in Italy', Applied and Environmental Microbiology 78, 3523-3529.

Dupont, H.L., Chappell, C.L., Sterling, C.R., Okhuysen, P.C., Rose, J.B. \& Jakubowski, W., 1995, 'The infectivity of Cryptosporidium parvum in healthy volunteers', New England Journal of Medicine 332, 855-859.

Fenwick, A., 2006, 'Waterborne infectious diseases - Could they be consigned to history?', Science 313, 1077-1081.

Gait, R., Soutar, R.H., Hanson, M., Fraser, C. \& Chalmers, R., 2008, 'Outbreak of cryptosporidiosis among veterinary students', Veterinary Record 162, 843-845.

Garcia, L.S., 2001, Diagnostic medical parasitology, ASM Press, Washington, DC.

Gatei, W., Das, P., Dutta, P., Sen, A., Cama, V., Lal, A.A. et al., 2007, 'Multilocus sequence typing and genetic structure of Cryptosporidium hominis from children in Kolkata, India', Infection, Genetics and Evolution 7, 197-205.

Gatei, W., Wamae, C.N., Mbae, C., Waruru, A., Mulinge, E., Waithera, T. et al., 2006 , 'Cryptosporidiosis: Prevalence, genotype analysis, and symptoms associated with infections in children in Kenya', American Journal of Tropical Medicine and Hygiene 75, 78-82.

Geurden, T., Goma, F.Y., Siwila, J., Phiri, I.G.K., Mwanza, A.M., Gabriel, S. et al., 2006 'Prevalence and genotyping of Cryptosporidium in three cattle husbandry systems in Zambia', Veterinary Parasitology 138, 217-222.

Helmy, Y.A., Krücken, J., Nöckler, K., Von Samson-Himmelstjerna, G. \& Zessin, K.-H., 2013, 'Molecular epidemiology of Cryptosporidium in livestock animals and humans in the Ismailia province of Egypt', Veterinary Parasitology 193, 15-24.

Hunter, P.R. \& Thompson, R.C.A., 2005, 'The zoonotic transmission of Giardia and Cryptosporidium', International Journal for Parasitology 35, 1181-1190.

Kiang, K.M., Scheftel, J.M., Leano, F.T., Taylor, C.M., Belle-Isle, P.A., Cebelinski, E.A. et al., 2006, 'Recurrent outbreaks of cryptosporidiosis associated with calves among students at an educational farm programme, Minnesota, 2003', Epidemiology and Infection 134, 878-886.

Leav, B.A., Mackay, M.R., Anyanwu, A., O’Connor, R.M., Cevallos, A.M., Kindra, G. et al., 2002, 'Analysis of sequence diversity at the highly polymorphic Cpgp40/15 locus among Cryptosporidium isolates from human immunodeficiency virusinfected children in South Africa', Infection and Immunity 70, 3881-3890.

Maikai, B.V., Umoh, J.U., Kwaga, J.K.P., Lawal, I.A., Maikai, V.A., Cama, V. et al., 2011 'Molecular characterization of Cryptosporidium spp. in native breeds of cattle in Kaduna State, Nigeria', Veterinary Parasitology 178, 241-245.

Mor, S.M. \& Tzipori, S., 2008, 'Cryptosporidiosis in children in sub-Saharan Africa: A lingering challenge', Clinical Infectious Diseases 47, 915-921.

Morse, T.D., Nicolas, R.A.B., Grimason, A.M., Campbell, B.M., Tembo, K.C. \& Smith, H.V., 2007, 'Incidence of cryptosporidiosis species in paediatric patients in Malawi', Epidemiology and Infection 135, 1307-1315.

Moshabela, M., Pronyk, P., Williams, N., Schneider, H. \& Lurie, M., 2011 'Patterns and implications of medical pluralism among HIV/AIDS patients in rural South Africa', AIDS and Behavior 15, 842-852.

Nchito, M., Kelly, P. \& Sianongo, S., 1998, 'Cryptosporidiosis in urban Zambian children: An analysis of risk factors', American Journal of Tropical Medicine and Hygiene 59, 435-437.

Pruitt, K.D., Tatusova, T. \& Maglott, D.R., 2005, 'NCBI Reference Sequence (RefSeq): A curated non-redundant sequence database of genomes, transcripts and proteins', Nucleic Acids Research 33, D501-D504.

Putignani, L. \& Menichella, D., 2010, 'Global distribution, public health and clinical impact of the protozoan pathogen Cryptosporidium', Interdisciplinary Perspectives on Infectious Diseases 2010, 39.

Qi, M., Wang, R., Ning, C., Li, X., Zhang, L., Jian, F. et al., 2011, 'Cryptosporidium spp. in pet birds: Genetic diversity and potential public health significance', Experimental Parasitology 128, 336-340.

Ramirez, N.E., Ward, L.A. \& Sreevatsan, S., 2004, 'A review of the biology and epidemiology of cryptosporidiosis in humans and animals', Microbes and Infection $6,773-785$.

Ryan, U., Xiao, L., Read, C., Zhou, L., Lal, A.A. \& Pavlasek, I., 2003, 'Identification of novel Cryptosporidium genotypes from the Czech Republic', Applied and Environmental Microbiology 69, 4302-4307. 
Salyer, S.J., Gillespie, T.R., Rwego, I.B., Chapman, C.A. \& Goldberg, T.L., 2012, 'Epidemiology and molecular relationships of Cryptosporidium spp. in people, primates, and and molecular relationships of Cryptosporidium spp. in people, prima
livestock from Western Uganda', PLoS Neglected Tropical Diseases 6, 10.

Samie, A., Bessong, P.O., Obi, C.L., Sevilleja, J.E., Stroup, S., Houpt, E. et al., 2006, 'Cryptosporidium species: Preliminary descriptions of the prevalence and genotype distribution among school children and hospital patients in the Venda region, Limpopo Province, South Africa', Experimental Parasitology 114, 314-322.

Simela, L., 2012, 'Options for the delivery of primary animal health care for livestock farmers on communal land in South Africa: Mnisi Community case study', MSc dissertation, University of Pretoria.

Siwila, J., Phiri, I.G., Enemark, H.L., Nchito, M. \& Olsen, A., 2011, 'Seasonal prevalence and incidence of Cryptosporidium spp. and Giardia duodenalsi and associated diarrhoea in children attending pre-school in Kafue, Zambia', Transactions of the Royal Society of Tropical Medicine and Hygiene 105, 102-108.

Smith, K.E., Stenzel, S.A., Bender, J.B., Wagstrom, E., Soderlund, D., Leano, F.T. et al. 2004, 'Outbreaks of enteric infections caused by multiple pathogens associated with calves at a farm day camp', Pediatric Infectious Disease Journal 23, 1098-1104.
Strong, W.B., Gut, J. \& Nelson, R.G., 2000, 'Cloning and sequence analysis of a highly polymorphic Cryptosporidium parvum gene encoding a 60-kilodalton glycoprotein and characterization of its 15 - and 45 - Kilodalton Zoite surface antigen products', Infection and Immunity 68, 4117-4134.

Thrusfield, M.V., 2007, Veterinary epidemiology, 3rd edn., Blackwell Science, Oxford.

Tumwine, J.K., Kekitiinwa, A., Nabukeera, N., Akiyoshi, D.E., Rich, S.M., Widmer, G. et al., 2003, 'Cryptosporidium parvum in children with diarrhea in Mulago Hospital, Kampala, Uganda', American Journal of Tropical Medicine and Hygiene 68, 710-715.

Xiao, L., 2010, 'Molecular epidemiology of cryptosporidiosis: An update', Experimental Parasitology 124, 80-89.

Xiao, L. \& Feng, Y., 2008, 'Zoonotic cryptosporidiosis', FEMS Immunology and Medica Microbiology 52, 309-323.

Xiao, L., Sulaiman, I.M., Ryan, U.M., Zhou, L., Atwill, E.R., Tischler, M.L. et al., 2002, 'Host adaptation and host-parasite co-evolution in Cryptosporidium: Implications for taxonomy and public health', International Journal for Parasitology 32, 1773-1785. 